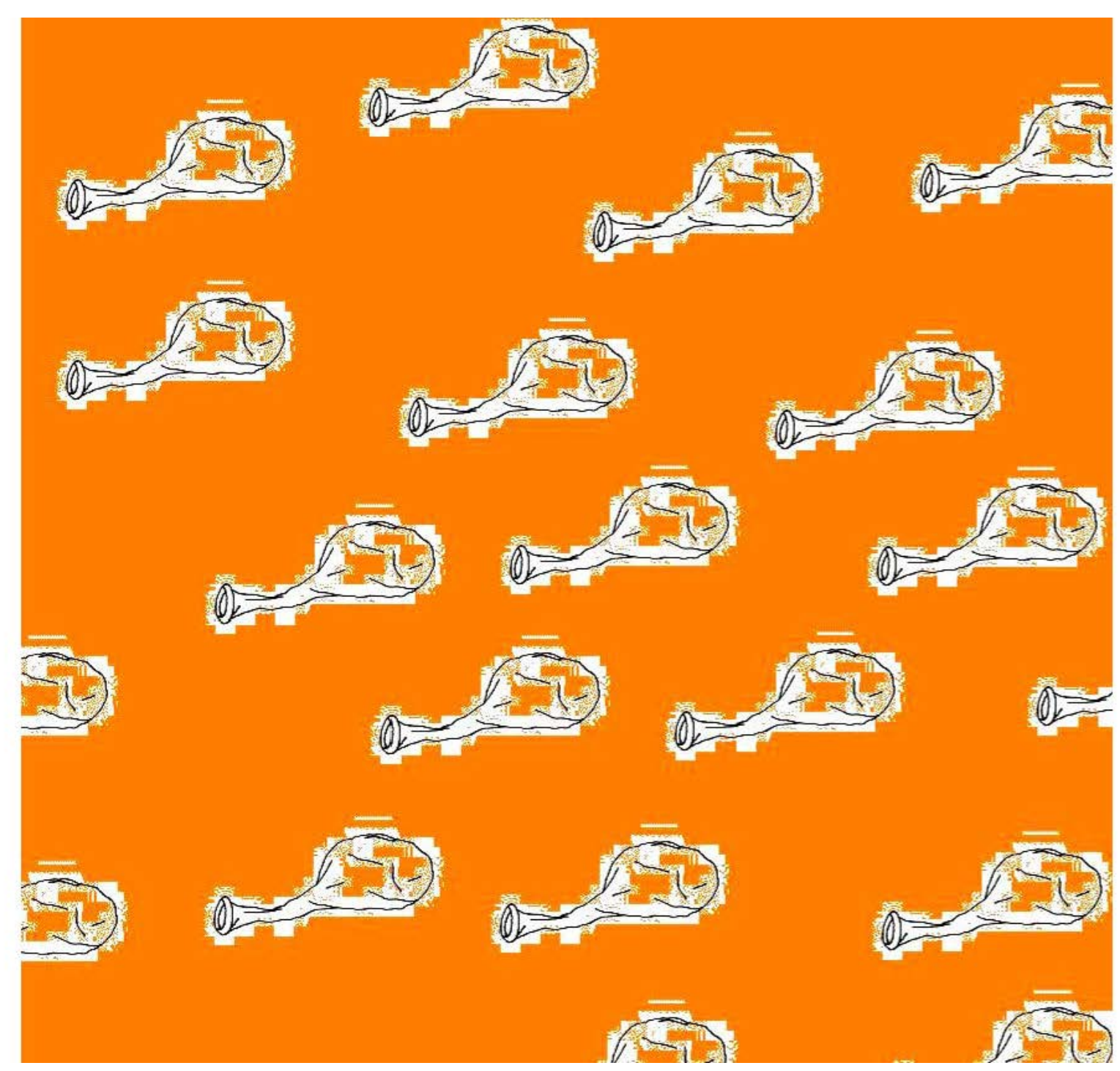




\section{mil house:}

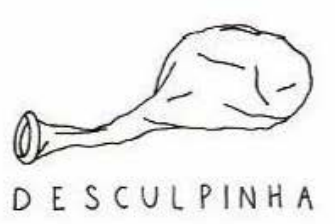

Galeria Espaço Piloto

Universidade de Brasília

Brasília - DF, 2015 


\section{Ficha Técnica}

\section{UnB IdA VIS Espaço Piloto}

Assessoria de Coordenação

Júlia Moana - Renata Malheiros

Audiodescriçōes

Grupo Acesso Livre (UnB)

Coordenação:

Charles Teixeira (LET/IL) - Soraya Ferreira (LET/IL)

Chefia do VIS

LuisaGünther

\section{Conselho Curatorial}

Christus Nóbrega - Elder Rocha Lima - Renata Azambuja

Coordenação

Cayo Honorato

Direção do IdA

Ricardo Freire

Júri de Seleção da Convocatória 2014-2015

Cecília Mori - Christus Nóbrega - Elder Rocha Lima

Limpeza

Antonina Soares - Isaias Dias - Maria Helena Dias - Teresinha de Jesus

Reitoria da UnB

Ivan Camargo Batman 


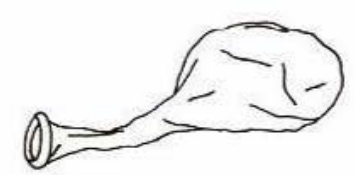

\section{Ateliê aberto}

07 a 20.05 .2015

oficinas 18,19 e 20.05 .2015

Exposição

26 a 16.05 .2015

\section{Galeria Espaço Piloto}

Ed. de Oficinas Especiais, Bloco A

Campus Darcy Ribeiro, Universidade de Brasília 
"Quanto por um tomate?"

\section{Milhouse van Houten}


Catálogo

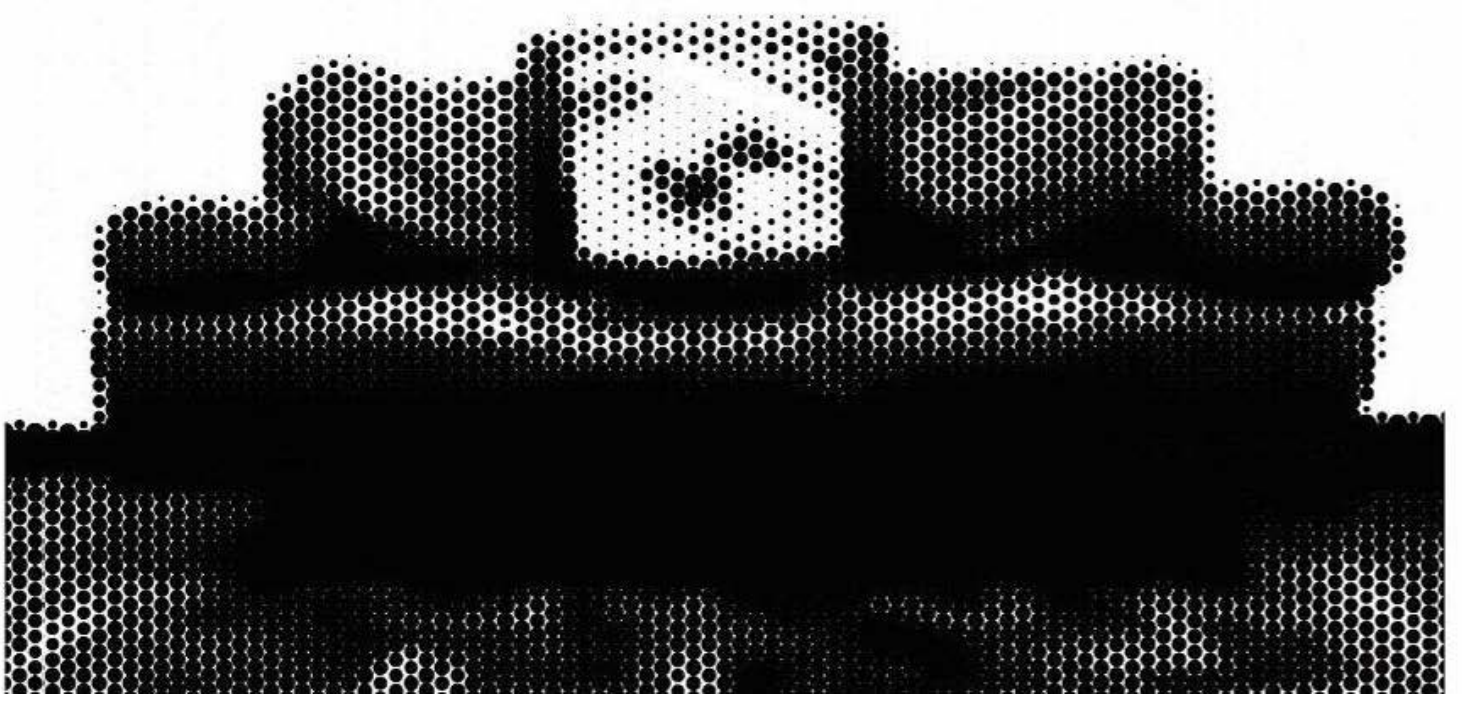


Quantas lâmpadas pra se trocar uma escada? instalação 2015 
Fase do castelinho Papel craft e video-game

2015 
Miss Universo gótica da série Dicas de Make

Giz de cera, nanquim, batom preto Contém $1 \mathrm{~g}$, base Mac, lápis de olho Jequiti, lágrimas 
Polenguinho sem amor giz e rapadura sobre papel sulfite rasgado 2015 
14 filhotinhos 
Iraquiana

capim-santo e spray sobre tela

$$
2015
$$


Não fui eu quem disse isso, mas fui eu quem desenhou lápis de cor e giz de cera sobre brinquedo

2015 
Insetos minúsculos branco sobre preto

$$
2015
$$


Sinfonia do desastre Giz de cera, video-instalação e pipoca

$$
2015
$$


A colheita do milho bala de prata, video-performance e azeite 
Luto canino

carvão e cera sobre papel

$$
2015
$$


Um coletivo na galeria.

O coletivo, diz lá o dicionário: "é substantivo que, estando no singular, designa o que está no plural." É $1+1+1+1+n$ ao infinito. Tripulação, coro, comunidade, time, trupe, bando. Todos denominam substantivos coletivos de pessoasinvestindo energia individual em grupo para chegar a um lugar comum.

Quando o coletivo encontra a arte, o lugar comum é a partilha. Uma contaminação que não tem endereço certo. $\mathrm{O}$ alvo não aquele ponto central para onde a flecha mira. Também não é o imaculado. Está mais para o que designa a arte em suas muitas concepções: é diabrura e é ofício; é mídia e é travessura. Quando um conjunto de artistas se encontra para inventar, o que resulta é multimodal.

Na transfiguração de linguagens pela potência da invencionice está o Desculpinha. Lá, dentro do cubo branco, que virou um penetrável, posicionaram-se doze artistas com suas ideias sobre arte. Há o $C, 0 s D, o H, o$ J, o K, aL, aN, o R, asT e o Y. Aqui em ordem alfabética, mas lá embaralhados. Com eles, o espaço introspectivo sorriu e deixou para trás a sua habitual auto-referência para se tornar alter-referente: comunicou-se com outros e com suas fantasias. Permitiu-se ser outro lugar de (para) arte. O Desculpinha, coletivo de pessoas artistas, entrou na galeria.

\section{Renata Azambuja}

Junho/2015 
Assim tá bom demaaais Canetão preto sobre pele

$$
2015
$$


Caminhada no Espaço

ação performática no Espaço, duração de 2 horas terrestres

2015 
Galinha oca

encave sobre galinha

$$
2015
$$


Supermercado Summerpecado jujuba, giz pastel e fita crepe sobre papelão 
Ternurinh a de amigos tinta mista sobre pano 2003 
Não fui eu que assinei Nanquim, acrílica, giz de cera sobre papel sufite 1986 
Chão de língua e dobradura sistema de irrigação com Arduíno

2015 
O Sequestro de MaurícioS.

Carvão sobre papel 180 gramas

2015 
Passarinho do abs

tinta, giz, e alguma coisa mais sobre papel

2015 
Procedimento cirúrgico de tradução não humana instalação com espelhos, brinquedos infláveis e lâminas de barbear 
Desvio para o amarelo

impressão 3D com fibra de vidro

$$
2014
$$




\section{DEgGULPANAA}

Q QuE DIZER deSSA EXPO QUE mAL CONHECO E JÁ CONSIDERO PACAS?

- colerio ispoce piloto.

* cortindo do neciós zu aguie

di vodivg arie,

ceteria

* ollisto estior de processo.

- ne diki alcite it nocesso

\&́ wibles, arte í o true $x$ mosira vios actios (?), al

inosirar vos outros previuzade

vumno polerio de crie i

rucens como orte

- Pior viu fkied

+ TO InTO CIAPAPOA

DSSS

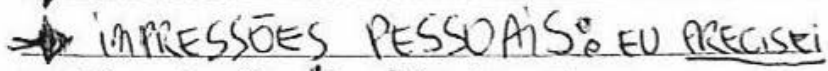

FUMAR 1 PRA VIIR PRA GALERIA, ACLE CLE

ESTPR NO MEIO DAS RESSUAS SERIA 
PESCONFOCTAVE, GiCO UM POU CO TÚmipA.

MAS A CLAPACAO FAZ PRTE DE UMA Parte ${ }_{\text {KKK }}$ PA VIDA.

- MAs una tóra náo i uma coisa, rodem ser coisas diflentes toda hora. a Amigos $\rightarrow$ ATELIE ABERTO $\Longrightarrow$ DESCONHECiDOS

- quero ir nas oficinas/Querer wód e poorr

- trocar ioéia sobre pintura, tintas telas
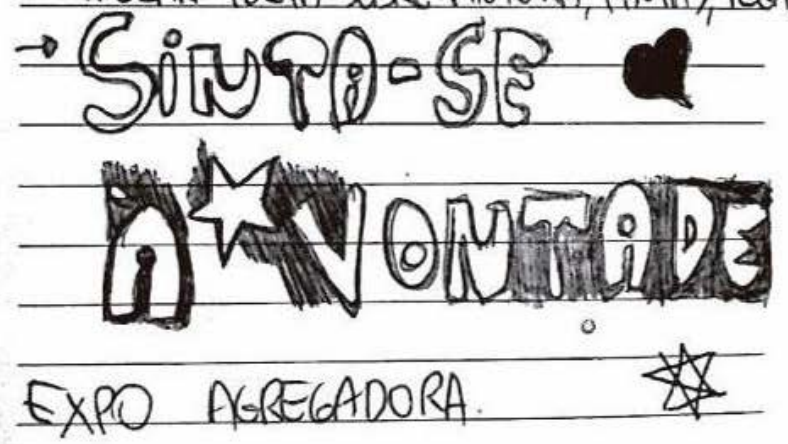

Chega aí vem fican de boa com nós NOIS 


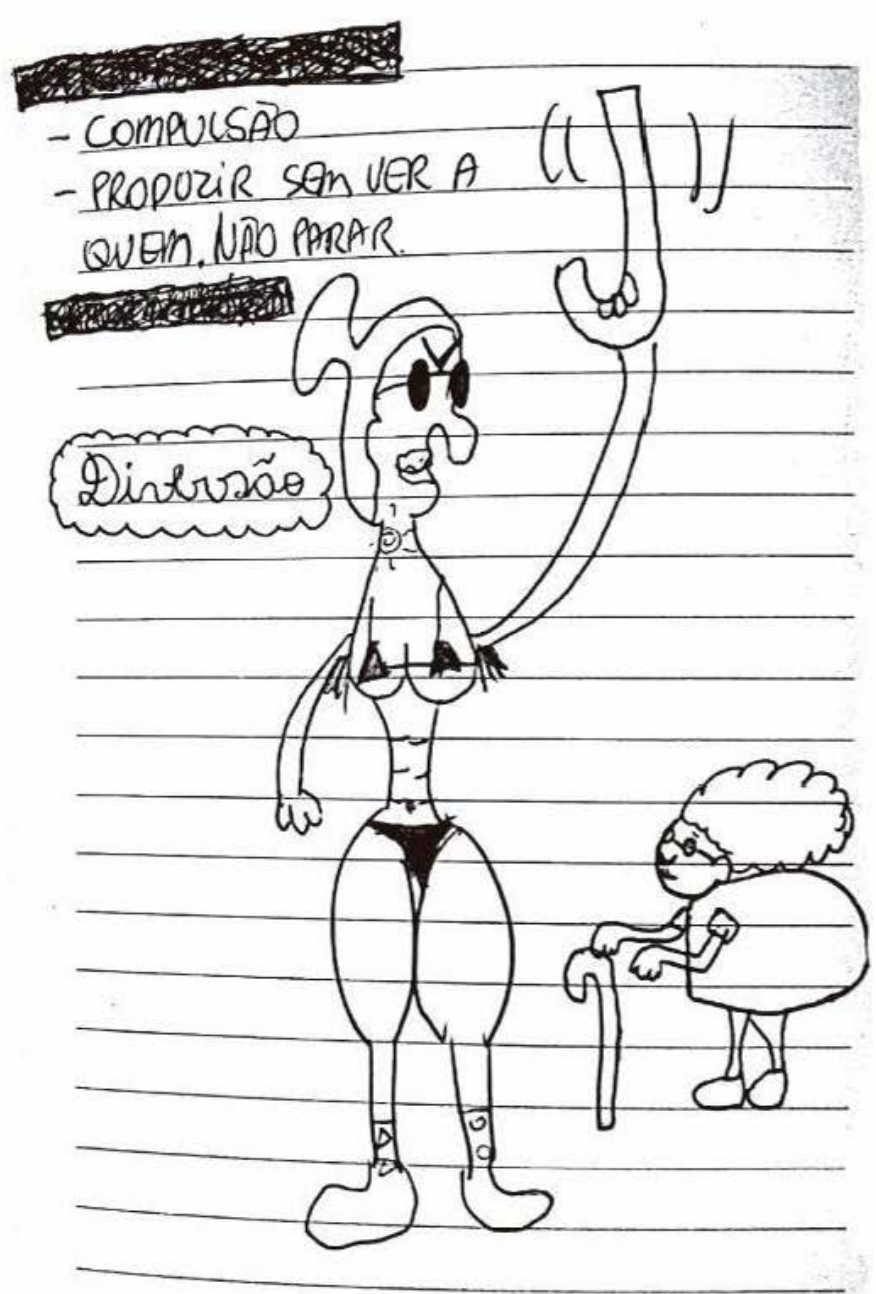

Bia Leite 
Amarelinha sem céu

giz sobre concreto sobre terra

2015 
Chama ele pro coletivo (eu quero pegar) Ação performática no Tinder, duração $1 \mathrm{~h} 37 \mathrm{~min}$

$$
2015
$$


Desculpas para o Fim do Mundo balão e áudio, $7^{\prime \prime}$ 
Três jeitos tortos de fazer torta

pastel seco e tinta acrilica sobre tela

$$
2015
$$


Cara, cadê meu carro? filme, 4' 20"

2015 
Trâmites na cachu aguada sobre pedra

$$
2015
$$


Desculpas para o Fim do Mundo

$$
\text { balão e áudio, } 7^{\prime \prime}
$$


"O altruísmo é o maior dos egoísmos" - KS do ghetu empasto de grafite sobre papel japonês 
Na padaria, a fila pastel oleoso sobre tela 2013-2015 (re-tocado) 
As aventuras dos PMinhos 
MIss Universo I

da Série Dicas de Make

Giz de cera, nanquim, batom vermelho Mac, cílios Mary Kay, base e pó Avon 
Lavoura Moderna

casco fendido, giz, gesso e esmalte sintético

2015 
Floresta Cristina

bolero para escaleta e derbak, $27^{\prime \prime}$

2014 
A disponibilidade me encanta. Ponto. Agora, será que esta declaração poderia ser suficiente para transpor, em palavras, a sensação que me foi causada após meu primeiro contato com o Coletivo Desculpinha?! Ou seria melhor fazer um desenho?! Hummm! Difícil escolha. Seria melhor desenhar, sem dúvida. No entanto, ao propor um desenho meu, estaria justamente confrontando, de forma tosca, esta proposta de ocupação do Espaço Piloto: um desenho meu, seria somente isto (ou seja: pouco) e é preciso mais do que isto. Principalmente, se a disponibilidade for considerada uma forma de resistência contra contextos indelicados, atitudes mesquinhas ou pessoas recalcadas. Ora, a disponibilidade é uma provocação sutil que questiona quais seriam os motivos sinceros de qualquer um não se deixar levar pela sinestesia do momento; pela amplitude de experiências possíveis; pela incompletude de tudo que ainda não aconteceu. Com isto, talvez estas palavras sejam, tão somente, singelas ocupações no espaço desta folha. Poderiam compor um ritmo de movimento, quase como uma coreografia, caso não sejam formatadas de forma alinhada. Ou, talvez, eu ainda não tenha composto, realmente, o que quero escrever. Enquanto esta dúvida paira por entre meus dedos neste teclado e minhas recordações de algo já acontecido, continuo encantada com a disponibilidade do Coletivo Desculpinha em agregar intençōes dinâmicas para existirem juntos; para desenhar; para que tudo continue a transbordar enquanto um momento no qual muito pode acontecer, basta querer e permitir. Com isto, retomo minhas recordações daquele momento de nosso primeiro encontro no qual me transbordei de percepções e questionei, a mim mesma, qual seria o limite entre uma proposição-clarkiana e a atuação de um coletivo de artistas que 
desmanchava o conceito de autoria em desenhos colaborativos? Ao brincar com esta pergunta por entre minhas entranhas deixei-me levar por questōes de índices experimentais que habitam certos conteúdos que transitam pela distinção entre verdades e incertezas; entre conhecimentos e saberes; entre contextos e instâncias do instituído e do instituinte. Confesso que tenho um sincero apreço pelos momentos que instauram sutis desencaixes anacrônicos de modo a conciliar uma prática contemporânea em arte com a exemplaridade histórica sem que para isto seja necessário incorrer ao óbvio. Poderia remoer tantos exemplos em uma escrita apropriada; em um esforço reflexivo sobre as possibilidades que ainda não estão, mas que poderiam ser. Ah! Coletivo Desculpinha (...) se vocês soubessem que nada disto importa. Tenho consciência que a reflexividade sozinha não engendraria estas possibilidades; a reflexividade sozinha não esgota a insistência da alteridade em ser outra coisa para além daquilo que a compreensão pretende. Tampouco uma exegese, como se estas palavras aqui concatenadas pudessem dimensionar uma cartografia singular da (des)hierarquia e do (trans)hibridismo napoética contemporânea do desenho enquanto intenção-ampliada. Enfim. Por entre os meandros e melindres daquilo que permaneceu em minhas entranhas este seria justamente o ponto de ruptura entre a prática do artístico enquanto desígnio e o formalismo como estrutura que pré-condiciona uma poética. Se a ocupação proposta apalpou - Espaço Piloto com um arcabouço para o desenhar enquanto exposição de si e de entrega para o outro, invariavelmente remeto isto a uma única condição libertária: viva o amor! Por tudo isto, gratidão.

\section{Luisa Günther}


Tradução do Forno

carvão e fogo sobre papelão

2015 
Myajii, Bruberd, Boyzim e Capirofofo

da Série Abracinhos

Papelão, acrílica, lã e fita adesiva 
Passarinho do abs

tinta, giz, e alguma coisa mais sobre papel

2015 
Procedimento cirúrgico de tradução não humana instalação com espelhos, brinquedos infláveis e lâminas de barbear 
Cardiograma 1 peito sobre mundo 2015 
A Dádiva

performance contínua na área externa

2015 
Desculpa mâe

Performance de duração de 3 horas, karaokê, pipoca, tv 24 polegadas, ausência e Simoni 
Novinho Experiente

grafite e sabedoria sobre corpo

2015 
A última respiração de uma clorofila fotografia 
Ultimamente nada que eu faça eu faço pensamento sobre ócio

2015 
Rosto de rito

máscara impressa

2015 
Oficina Filosofia Milhouse em balôes

Registro fotográfico

18.05.2015 
Oficina Cospobre Vanguarda

Registro fotográfico

19.05.2015 
Oficina de Quadrinhos Higiênicos

Registro fotográfico

20.05.2015 
Gostaria di agradicê a todos que fazem parte do coletivo por ampliar minhas perspectivas artísticas, a libertação do ego e a vontade de se aventurar se expressando com simplicidade. Fazer essa transa com vocês foi demais! Grande beijo e sucesso a todos!

Please come tu Recife. $<3$

\section{Sosha}




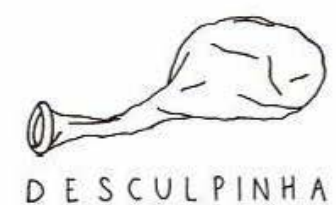

DESCULPINHA

\author{
Cainan Rodrigues \\ Danna Lua Irigaray \\ Diego Torres \\ Heron Prado \\ Jan Araújo \\ Kabe Rodríguez \\ Livia Viganó \\ Nana Bittencourt \\ Rodrigo Koshino \\ Taís Koshino \\ Thalita Perfeito \\ Yuri Thevenard
}

www.coletivodesculpinha.com.br 


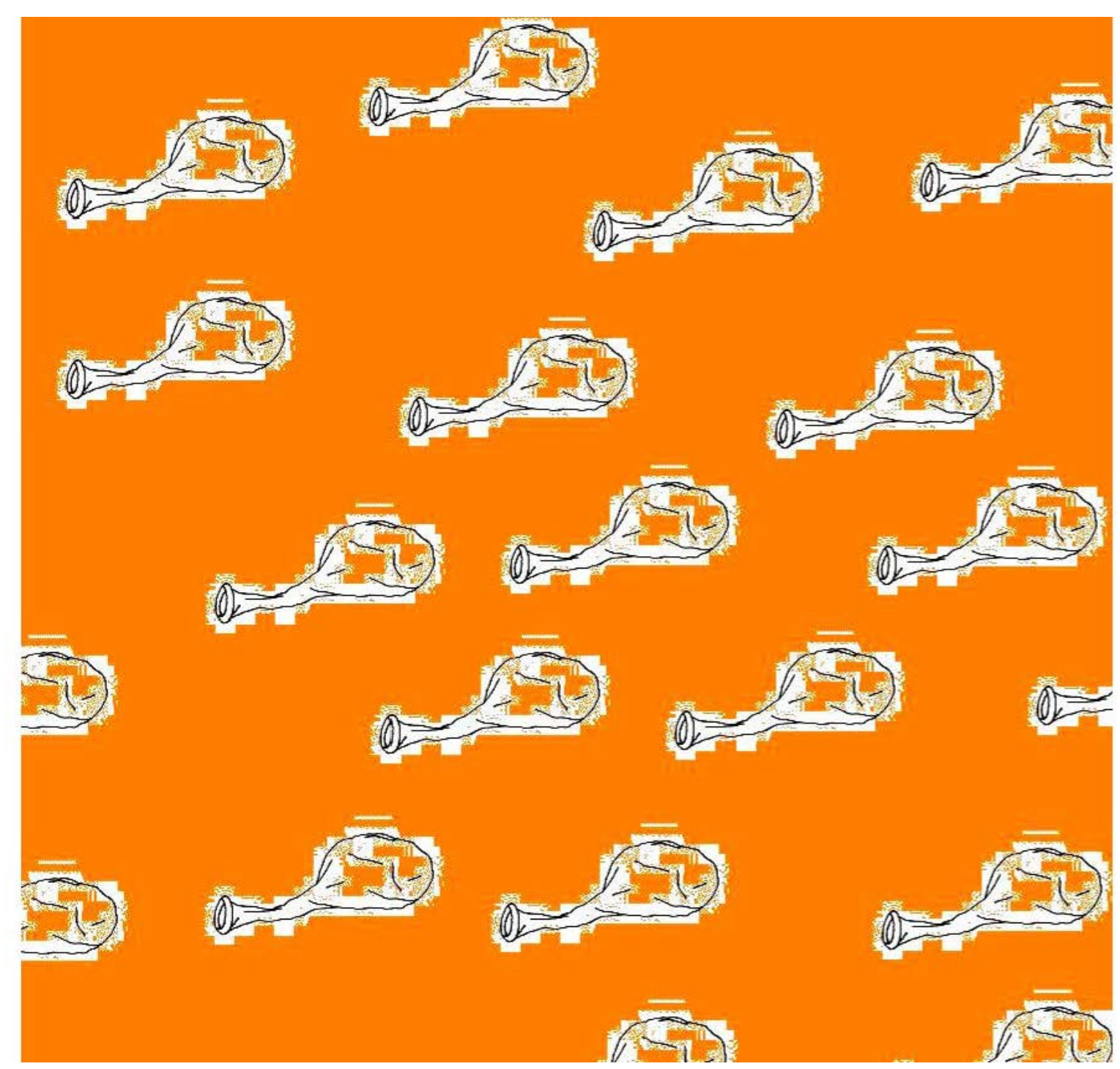

